\title{
Incisional surgical site infections in obstetric and gynecological procedures in a tertiary care hospital in Northern India
}

\author{
Savita Chandra*, Shodashi Saxena
}

Department of Obstetrics \& Gynecology, Era’s Medical College and Hospital, Lucknow, Uttar Pradesh, India

Received: 29 August 2020

Accepted: 06 October 2020

\section{*Correspondence:}

Dr. Savita Chandra,

E-mail: savitachandramd@gmail.com

Copyright: (C) the author(s), publisher and licensee Medip Academy. This is an open-access article distributed under the terms of the Creative Commons Attribution Non-Commercial License, which permits unrestricted non-commercial use, distribution, and reproduction in any medium, provided the original work is properly cited.

\begin{abstract}
Background: To find the incidence of incisional surgical site infection (ISSI) in obstetric and gynecological procedures, the risk factors, the microbial spectrum, the antibiotic sensitivity and the impact on the hospital stay. Methods: A prospective observational study was done under the department of obstetrics and gynecology, Era's Lucknow medical college and hospital. All consecutive patients who underwent caesarean section, vaginal delivery with episiotomy, laparotomy, and hysterectomy were included in this study. Laparoscopic surgeries were excluded. Results; In this series of 646 surgeries, $6.18 \%$ developed ISSI. In the category of major surgeries, the ISSI rate was 8.89\%. Amongst the 185 episiotomies $1.6 \%$ gaped. Anemia, diabetes mellitus, excess body weight, emergency or elective surgery, rapid built up of hemoglobin with blood transfusion, previous caesarean scar and tobacco intake were the risk factors identified. Coagulase negative staphylococcus was the dominant microbe. Antibiotic sensitivity to linezolid was found in $50 \%$ of the ISSI cases followed by amikacin, clindamycin and some others. The mean hospital stay was 13 days while the maximum was 26 days.

Conclusions: The study established the current status of incisional surgical site infections, identified the risk factors, the microbial spectrum, the antibiotic sensitivity and the need for further studies using a preventive approach.
\end{abstract}

Keywords: Incisional surgical site infections, Major obstetric and gynecological procedures, Episiotomy

\section{INTRODUCTION}

Even in current times, surgical site infections (SSI's) continue to be a common cause of postoperative morbidity. Consequently, there is increased use of antibiotics, extended hospital stays, added monetary cost both to the patient and to the health care facility, as well as increased emotional and psychological stress to the patient.

Globally the incidence of SSI's varies greatly. The overall SSI rate in developed European countries is $3 / 100$ surgical procedures and that in the USA is $2.6 / 100$ surgical procedures. ${ }^{1}$ In gynecological surgery, the SSI rate of $1.7 \%$ is reported in the US, according to the center for disease control (CDC), USA. ${ }^{2,3}$ In developing countries like India, SSI rates vary from $10-33 \%$ i.e. three to ten times higher than in the developed countries. ${ }^{4}$

This wide global variation in the rates of SSI could be attributed to several factors related to the patient, surgery, the technical skill, the standard of sterilization of the surgical equipment, hospital environment, and the climate.

We believe that these factors interplay and have a significant bearing on the biological complex molecular interactions and mechanisms of wound healing unique to each patient and not yet fully understood. Understanding this complex interaction could explain why some patients develop SSI while others do not. 
As per the modified CDC classification, surgical site infections can be divided into three groups i.e. superficial incisional surgical site infections, deep incisional surgical site infections and organ/space surgical site infections. ${ }^{5}$

While there are several studies on the overall SSI's, there is however paucity of studies exclusively on ISSI in obstetrical and gynecological (OBG) surgical procedures.

With this in mind, the present study was planned to find the incidence of ISSI, the underlying microbiological bacterial spectrum, the antibiotic sensitivity, the risk factors, and the duration of hospital stay.

\section{METHODS}

This was a prospective observational study conducted in 2019 in the Department of Obstetrics \& Gynecology of Era's Lucknow medical college and hospital. This is, to our knowledge, the very first study of its kind in the department. Approval from the research and ethical committee of the institution was obtained.

\section{Inclusion criteria}

All consecutive patients who underwent caesarean section, vaginal delivery with episiotomy, laparotomy, and hysterectomy were included in this study.

\section{Exclusion criteria}

Laproscopic surgical procedures, patients who had undergone OBG surgeries elsewhere, but admitted postoperatively in the department; those admitted with SSI's 30 days after discharge, patients with history of febrile illness within the preceding fortnight, those with amniotic fluid leaking per vaginum for more than 6 hours, skin infection, burning micturition, chronic cough, sore throat, bronchitis, chronic obstructive pulmonary disease, and vaginal deliveries without episiotomy were excluded.

History and demographic information of the enrolled subjects was recorded.

For major OBG surgeries, preoperative scrubbing was done using standard chlorhexidine and betadine solution sequentially. Skin preparation for vaginal deliveries was done using only chlorhexidine. Only the vaginal deliveries with episiotomy were included.

All patients for major surgeries were administered an intravenous dose of antibiotic (either one-gram ceftriaxone or cefoperazone sulbactam as per choice of the primary surgeon),15-30 minutes prior to the surgical incision.

Majority of the caesarean sections were performed by senior residents while the high-risk ones by the junior/senior faculty. All hysterectomies were performed by junior/senior faculty as per the merits of the case.
After the abdominal closure, the site was cleaned antiseptically and a sealed wound dressing was applied. Post-operatively, all major cases received $100 \mathrm{mg}$ metronidazole intravenously 8 hourly and gentamycin 60 to $80 \mathrm{mg}$ intramuscularly unless contraindicated.

The primary wound dressing was removed on the $3^{\text {rd }}$ post- operative day. Thereafter, daily antiseptic dressings were done, observations noted, and grouped into superficial and deep incisional surgical site infections based on the standard modified CDC criteria. ${ }^{5}$ Wound discharge was sent for culture and sensitivity.

Majority of the vaginal deliveries were conducted by junior/senior resident doctors. Catgut was used for suturing the episiotomy. All were mediolateral episiotomies. Oral antibiotics were given as per the merits of the case.

The data was analyzed using statistical package for social sciences (SPSS, version 16). $\mathrm{P}$ value $<0.05$ was considered significant.

\section{RESULTS}

Out of the 646 enrolled cases, the youngest patient was 19 years and the oldest was 71 years. 602 cases $(93.19 \%)$ had no incisional surgical site infections (ISSI) while 44 cases $(6.81 \%)$ developed superficial incisional wound infection. There was no case of deep incisional surgical site infection in this series.

Amongst the 646 cases, 461 were major surgical procedures while 185 were episiotomies. Amongst the major surgeries 41 developed ISSI (8.8\%). Amongst the episiotomies 3 gaped (1.6\%) Further, it was found that of the 41 ISSI cases, 32 i.e. $78.1 \%$ were caesarean sections, $14.6 \%$ were total abdominal hysterectomies (TAH) and $7.3 \%$. were laparotomies (LAP), the p value was significant (Table 1).

Of the major obstetric cases, 335 were caesarean sections, and 14 were laparotomies (Table 1). Previous caesarean scar was present in 13 of the 32 cases with ISSI i.e. $40.6 \%$ of caesarean sections.

Amongst the 461 major surgeries, 174 were elective and 287 were emergency surgeries (Table 2) Out of the elective cases $3.45 \%$, while $12.20 \%$ of the emergency surgeries developed ISSI. Thus, ISSI was four times more in the emergency than in the elective surgery, $p$ value $<0.001$ which is statistically significant.

In the total 646 cases, there was no comorbidity in 209 cases (Table 3). Anemia was the dominant comorbidity present in 17 of the 44 ISSI cases $(38.6 \%)$, followed by diabetes mellitus in $11.4 \%$. Thus, anemia and diabetes mellitus together added to $50 \%$ of the 44 ISSI cases. The Odds ratio for diabetes mellitus was 3.73 which was the highest. 
Table 1: Distribution according to the major surgical procedure.

\begin{tabular}{|c|c|c|c|c|c|c|c|c|c|}
\hline \multirow[b]{2}{*}{ Procedures } & \multirow{2}{*}{$\begin{array}{l}\text { Major } \\
\text { surgeries } \\
(\mathbf{n}=\mathbf{4 6 1})\end{array}$} & \multirow{2}{*}{$\begin{array}{l}\text { No. without } \\
\text { ISSI } \\
(n=420)\end{array}$} & \multirow{2}{*}{$\begin{array}{l}\text { No. with } \\
\text { ISSI } \\
(n=41)\end{array}$} & \multirow{2}{*}{$\begin{array}{l}\% \text { of } \\
\text { total } \\
(n=461)\end{array}$} & \multirow{2}{*}{$\begin{array}{l}\% \text { of } \\
\text { ISSI } \\
(n=41)\end{array}$} & \multicolumn{2}{|c|}{$95 \% \mathrm{CI}$} & \multirow{2}{*}{$\begin{array}{l}\text { Chi } \\
\text { square }\end{array}$} & \multirow{2}{*}{$\begin{array}{l}\mathbf{P} \\
\text { value }\end{array}$} \\
\hline & & & & & & CIL & CIU & & \\
\hline $\begin{array}{l}\text { Total } \\
\text { abdominal } \\
\text { hysterectomy }\end{array}$ & 49 & 43 & 6 & 1.3 & 14.6 & 3.1 & 21.4 & 4.54 & 0.033 \\
\hline $\begin{array}{l}\text { Laparotomy } \\
\text { (gynecological) }\end{array}$ & 23 & 22 & 1 & 0.2 & 2.4 & 0.0 & 12.7 & 8.05 & 0.005 \\
\hline $\begin{array}{l}\text { Laparotomy } \\
\text { (obstetric) }\end{array}$ & 14 & 12 & 2 & 0.4 & 4.9 & 0.0 & 32.6 & 7.50 & 0.006 \\
\hline $\begin{array}{l}\text { Vaginal } \\
\text { hysterectomy }\end{array}$ & 38 & 38 & 0 & - & 0.0 & 0.0 & 0.0 & 11.79 & $<0.001$ \\
\hline $\begin{array}{l}\text { Manchester's } \\
\text { operation }\end{array}$ & 2 & 2 & 0 & - & 0.0 & 0.0 & 0.0 & 8.83 & 0.003 \\
\hline $\begin{array}{l}\text { Caesarean } \\
\text { hysterectomy }\end{array}$ & 1 & 1 & 0 & - & 0.0 & 0.0 & 0.0 & 8.75 & 0.003 \\
\hline LSCS & 334 & 302 & 32 & 6.9 & 78.1 & 6.4 & 12.7 & 7.68 & 0.005 \\
\hline Total & 461 & 420 & 41 & 8.8 & 100 & & & & \\
\hline
\end{tabular}

Table 2: Post-operative wound infection rates in emergency vs elective cases.

\begin{tabular}{|lllll|l|} 
Type of surgery & $\begin{array}{l}\text { Major surgeries } \\
(\mathbf{n = 4 6 1 )}\end{array}$ & $\begin{array}{l}\text { Number of ISSI } \\
(\mathbf{n = 4 1 )}\end{array}$ & $\begin{array}{l}\text { Percentage of total elective or } \\
\text { emergency cases }(\%)\end{array}$ & $\begin{array}{l}\text { 95\% CI } \\
\text { CIL }\end{array}$ & CIU \\
\hline Elective & 174 & 6 & 3.45 & 0.7 & 6.2 \\
\hline Emergency & 287 & 35 & 12.20 & 8.4 & 16.0 \\
\hline
\end{tabular}

chi square $=18.97, \mathrm{p}<0.001$

Table 3: Distribution of cases based on the risk factors.

\begin{tabular}{|c|c|c|c|c|c|}
\hline Risk factors & $\begin{array}{l}\text { Total cases } \\
(n=646)\end{array}$ & $\begin{array}{l}\text { Patients with ISSI } \\
(\mathrm{n}=44)\end{array}$ & $\begin{array}{l}\text { Percentage of ISSI cases } \\
(n=44)(\%)\end{array}$ & OR & P value \\
\hline Hypertension & 108 & 3 & 6.8 & 0.346 & 0.068 \\
\hline Anaemia & 245 & 17 & 38.6 & 1.2 & 0.920 \\
\hline Diabetes & 25 & 5 & 11.4 & 3.73 & 0.008 \\
\hline Jaundice (infective) & 12 & 1 & 2.3 & 1.25 & 0.833 \\
\hline Hypothyroidism & 15 & 1 & & 0.97 & 0.982 \\
\hline Urinary tract infections & 27 & 0 & 2.3 & NA & 0.151 \\
\hline Malaria & 5 & 0 & 0.00 & NA & 0.544 \\
\hline No comorbidity & 209 & 17 & 38.6 & & \\
\hline Total cases & 646 & 44 & 100 & & \\
\hline
\end{tabular}

Table 4: Distribution of cases with wound infection according to BMI.

\begin{tabular}{|lll|}
\hline BMI $\left(\mathrm{kg} / \mathrm{m}^{2}\right)$ & $\begin{array}{l}\text { Patients } \\
\text { with ISSI }\end{array}$ & $\begin{array}{l}\text { Percentage } \\
(\mathbf{n}=\mathbf{4 4})(\boldsymbol{\%})\end{array}$ \\
\hline $\mathbf{1 1 8}$ & 1 & 2.3 \\
\hline $\mathbf{1 8 - 2 4 . 9}$ & 16 & 36.4 \\
\hline $\mathbf{2 5}$ & 27 & 61.3 \\
\hline Total & 44 & 100 \\
\hline
\end{tabular}

It was observed that amongst the 41 major surgeries with ISSI, rapid build-up of hemoglobin was done with blood transfusions in 12 of the 41 cases i.e. $29.3 \%$. Of these 12 cases, 7 were caesarean cases, 2 were abdominal hysterectomies and 3 were laparotomies. Of the overall
44 patients who developed ISSI's, close to two thirds of the patients with ISSI were overweight i.e.61.3\% (Table 4).

It was observed that wounds with dehiscence of less than one third of the linear length with/without serous discharge healed with antiseptic wound dressings and change of antibiotics (Table 5). Additionally, wounds with purulent/serosanguinous discharge and/or dehiscence more than half the linear length required secondary surgical suturing.

In this study, 20 of the 44 ISSI wounds (45.4\%) had to be re-sutured. 
Table 5: Distribution based on wound discharge and appearance.

\begin{tabular}{|c|c|c|c|}
\hline $\begin{array}{l}\text { Wound appearance/ } \\
\text { wound discharge }\end{array}$ & $\begin{array}{l}\text { ISSI cases number and } \\
\text { type of surgical procedure } \\
(n=44)\end{array}$ & $\begin{array}{l}\text { Wound dehiscence } \\
\text { as fraction of linear } \\
\text { length }\end{array}$ & $\begin{array}{l}\text { Number of cases in } \\
\text { which secondary } \\
\text { suturing was done }\end{array}$ \\
\hline \multirow{2}{*}{$\begin{array}{l}\text { Erythema with minimal } \\
\text { discharge }\end{array}$} & 2-Episiotomy & \multirow[t]{2}{*}{ - } & \multirow{2}{*}{ Nil } \\
\hline & 5-Cesarean section & & \\
\hline Serous/watery & 8-Cesarean section & $<1 / 3^{\text {rd }}$ length & Nil \\
\hline \multirow[t]{2}{*}{ Serosanguinous } & $\begin{array}{l}\text { 2-Laparotomy } \\
\text { 7-Cesarean section }\end{array}$ & $\begin{array}{l}<\text { half length } \\
9 \text { cases }(7+2)\end{array}$ & Nil \\
\hline & 12-Cesarean section & $12>$ half length & $12 \mathrm{CS}^{*}$ \\
\hline \multirow{3}{*}{ Purulent } & 1-Episiotomy & \multirow{3}{*}{$\begin{array}{l}\text { Full length dehiscence } \\
8 \text { cases }(6+1+1)\end{array}$} & \multirow{3}{*}{$8(6+1+1)$} \\
\hline & $\begin{array}{l}\text { 1-Laparotomy } \\
\text { (ectopic pregnancy) }\end{array}$ & & \\
\hline & 6-Total Abd* hysterectomy & & \\
\hline Total ISSI cases & 44 & & $20(45.4)$ \\
\hline
\end{tabular}

$\mathrm{CS}=$ caesarean section; $\mathrm{Abd}=$ Abdominal

Table 6: Distribution based on the isolated microbial pathogen.

\begin{tabular}{|lllll|}
\hline Organisms isolated & Patients with SSI's & Percentage (n=44) $(\boldsymbol{\%})$ & 95\% CI & CIU \\
\hline E. coli & 6 & 13.7 & 3.5 & 23.7 \\
\hline Enterococcus species & 2 & 4.5 & 0.0 & 10.6 \\
\hline $\begin{array}{l}\text { Coagulase negative } \\
\text { Staphylococcus aureus }\end{array}$ & 12 & 27.3 & 14.1 & 40.3 \\
\hline Klebsiella pneumoniae & 3 & 6.8 & 0.0 & 14.2 \\
\hline Proteus vulgaris & 2 & 4.5 & 0.0 & 10.6 \\
\hline No bacterial growth & 19 & 43.2 & 28.5 & 57.7 \\
\hline Total & 44 & 100 & & \\
\hline
\end{tabular}

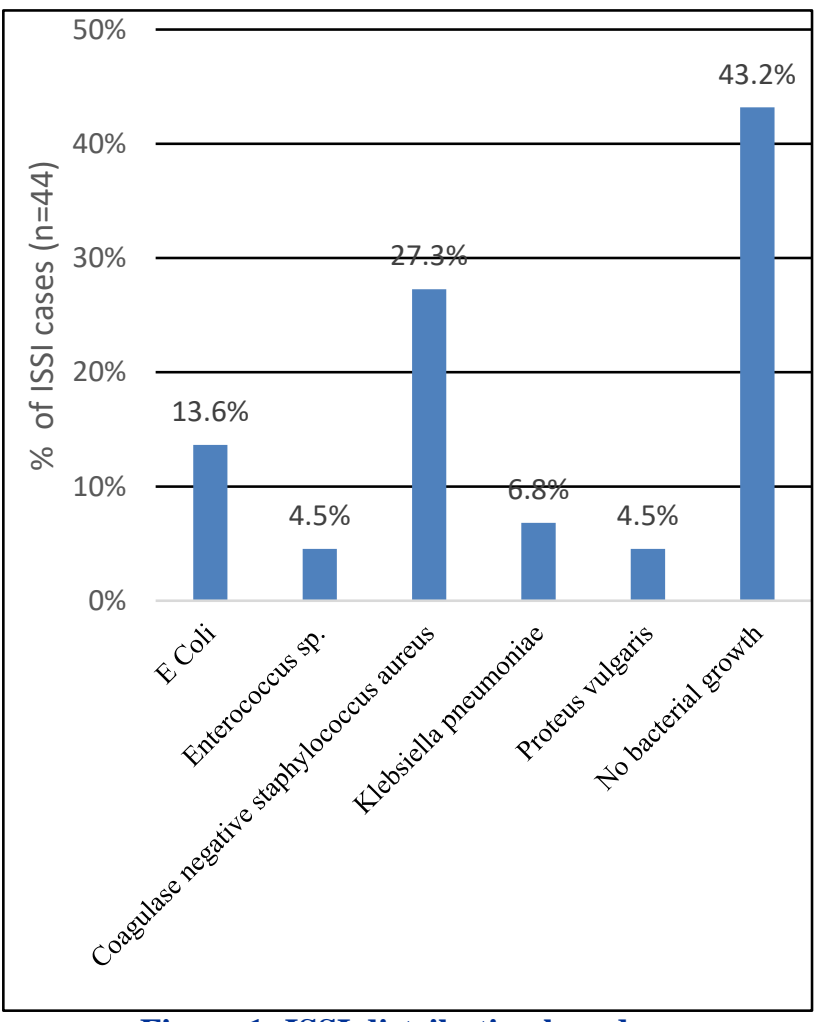

Figure 1: ISSI distribution based on microbial cultures.
Amongst the 41 major abdominal cases of ISSI, 28 $(68.3 \%)$ had received injection cefoperazone sulbactam pre-operatively, while $13(31.7 \%)$ patients had received ceftriaxone. Thus, injection ceftriaxone pre-operatively had lesser number of ISSI and so was the better choice.

Table 6 shows that coagulase negative Staphylococcus aureus was commonest microbe found in 12 of 44 ISSI cases i.e. $27.3 \%$, followed by E. coli in $13.7 \%$. Other microbes identified were Klebsiella pneumoniae, Enterococcus and Proteus vulgaris (Figure 1).

Microbiological cultures in 19 of the 44 ISSI cases were reported as sterile. Of the 25 cases with positive microbial cultures, $50 \%$ were sensitive to linezolid, $27.2 \%$, to clindamycin, and $11.3 \%$ to amikacin. The remaining were sensitive to other antibiotics (piperacillintazobactam, teicoplanin, meropenem).

\section{DISCUSSION}

Scientific studies suggest that about two thirds of SSI's are superficial, the remainder are deep and in organs, intraperitoneal or retroperitoneal. ${ }^{6}$ Gangane et al observed that $92.5 \%$ of SSI's in their study were superficial. In our study all cases of SSI were superficial ISSI. ${ }^{7}$ 
In this series of the 646 cases, the overall ISSI rate was $6.8 \%$ which is in close to $7.3 \%$ reported by Valecha et al. ${ }^{8}$ This series also included 185 episiotomies of which 3 gaped i.e. $1.6 \%$. Review of literature gives range for gaped episiotomy as $0.2-4.6 \% .^{9}$

When we excluded the 185 episiotomies, and considered only the 461 major surgeries, ISSI occurred in 41 cases i.e. $8.89 \%$. This is close to $7.83 \%$ reported by Pathak et $\mathrm{al}^{10}$ in their study. In our study caesarean sections constituted $78.1 \%$ of the 41 ISSI (Table 1). Also, none of the vaginal major surgeries developed ISSI (Table 1). Thus, the route and type of surgical procedure was identified as a risk factor for ISSI.

The incidence of wound complications in the obstetric population was reported as 2.8 and $26.6 \%$ by Myles and Chelmow et al in their studies respectively. ${ }^{11,12}$

In the series (Table 1), 32 of the 334 caesareans developed ISSI i.e.9.58\%, which is significantly lower than $18.66 \%$ reported by Shrestha et al and $23.5 \%$ by Cardoso et al but significantly higher than $2.74 \%$ reported by Pandit et al. ${ }^{14,15}$

Bhartiya et al in their study on 216 caesarean sections, at a tertiary hospital in New Delhi reported $88.4 \%$ as superficial SSI's, 9.3\% deep, and $2.3 \%$ organ $/$ space SSI's. ${ }^{13-16}$ Our findings are in strong contrast to those of Bhartiya et al study. ${ }^{16}$ The lower rate observed in our study could be attributed to the policy of administration of pre-operative injectable antibiotics in every major surgery and the policy of using interrupted sutures for closure of subcutaneous tissues. Additionally, other differences like number of elective/emergency cases in respective cohorts, suture materials used, patients with comorbidities etc, could account for the differences in the results.

In our series, 13 of the 32 caesarean sections (40.6\%) with ISSI had a previous caesarean scar. Narang et al in their study made a similar observation and found that $47 \%$ of their caesarean cases developed SSI had a previous scar. ${ }^{17}$

Of the 112 major gynecological cases in this study, $6.25 \%$ developed ISSI (Table 1), lower than $10.5 \%$ reported by Naphade et al in their study. ${ }^{18}$ Our policy of administration of pre-operative intravenous antibiotic in every case could have accounted for this difference.

Found that ISSI was four times higher in the emergency cases i.e. $12.1 \%$, against $3.4 \%$ in the elective cases (Table 2). Similar trend was observed by Bhadauria et al who reported $16.01 \%$ SSI in emergency and $3.67 \%$ SSI rate in elective surgeries. ${ }^{4}$ Narang et al in their study also observed this trend. ${ }^{19}$

We found that comorbidities were a risk factor for ISSI. Anemia was the leading comorbidity present in 17 of the
44 cases with ISSI i.e. $38.6 \%$ (Table 3) whilst diabetes mellitus held the second position. Tayade et al in their study also showed that anemia was the commonest risk factor for SSI. ${ }^{7}$

Anemia acts through hypo-oxegenation of the tissues which directly affects the wound healing, as well as predisposes the wound to new post- operative infection. Pre-operative anemia is thus an important risk factor for predicting SSI's and has been proved by several other studies. ${ }^{20}$ Further, it was noticed that in $29.3 \%$ of the 41 ISSI cases, hemoglobin was built rapidly through blood transfusions. So, though surgery was accomplished, but rapidly building up the hemoglobin did not actually translate into 'good' tissue health. Therefore, we hypothesize that rapid built up of hemoglobin may itself be a risk factor for ISSI. Case controlled studies will have to be done to evaluate our hypothesis.

With regard to diabetes mellitus as a risk factor for SSI, the higher blood sugar in the diabetics impairs the function of the white blood corpuscles which are central to the role of the immune system. Diabetics also have less collagen production which also slows wound healing; further they have slower blood circulation so delivery of nutrients to the site of wound healing is slower.

Excess weight was found to be a risk factor for ISSI. In this series, $68.1 \%$ were overweight with BMI more than 25 (Table 4) Ibrahim et al also observed that excess weight/obesity was a risk factor for wound infections. ${ }^{21}$ Thus, a preventive approach to reduce SSI would be, to enhance effort to increase the general awareness of life style health issues and the benefits of maintaining an optimal weight and health. This approach may not be possible for emergency surgeries but needs to be considered for elective surgeries where, if feasible, a longer time frame could be considered, before elective surgery, to allow the patient to take necessary corrective steps towards life style issues which in turn, could cut down operative and post- operative morbidity.

$54.6 \%$ of the ISSI cases healed with conservative measures but $45.4 \%$ had to undergo re-suturing (Table 5). Reviewing these cases more closely, we found that the majority of the women who developed ISSI were addicted to chewing tobacco rolled in beetle leaves colloquially called "PAAN". Nicotine in tobacco thus hindered wound healing and weakened the patient's natural immune system and so was an important contributory risk factor for ISSI. This was again a life style issue.

It was a consolation to know that the need for secondary re-suturing in our study was much lower (45.4\%) than that of Naphade et al where $71 \%$ patients needed secondary suturing. ${ }^{18}$ These significant variations in the results could be attributed to the differences in the enrolled subjects in the two studies in terms of their comorbidities, life styles, socioeconomic categories, 
hospital and environmental factors etc. The study also gave us an insight that further understanding and improvement needs to be done to reduce ISSI and the rates of secondary surgical re-suturing.

Based on the observations, we recommend that when ISSI exceeds half the linear length of the wound, secondary surgical suturing should be adopted at the earliest, rather than persisting with hopeful conservative approach resulting in unduly prolonged hospital stay. In this study, the maximum hospital stay of patients with ISSI was 26 days and their average hospital stay was 13 days.

In this study among the 25 positive cultures, coagulase negative Staphylococcus aureus was the most common pathogen identified in $27.3 \%$, followed by $E$. coli in $13.7 \%$, Klebsiella pneumoniae in $6.8 \%$, Enterococcus species in $4.5 \%$ and Proteus vulgaris in $4.5 \%$. Fehr and Erikson et al in their studies also found Staphylococcus aureus and E. coli as the leading pathogens from infected wounds. ${ }^{21,22}$

However, Shrestha et al in their study found that Acinetobacter species, was the most common organisms isolated in $32.03 \%$, followed by Staphylococcus aureus in $20.41 \%$ and Coagulase negative Staphylococcus in $13 \% .^{13}$ Dahiya et al in their study reported $E$. coli as the most common organism found in $25.93 \%$ of their cases. ${ }^{23}$

Regarding the antibiotic sensitivity, 50\% were sensitive to linezolid, $27.2 \%$ to amikacin, $11.3 \%$ to clindamycin. The remaining $11.3 \%$ were sensitive to higher antibiotics like piperacillin-tazobactam, teicoplanin, and meropenem. Bhadauria et al found $E$. coli to be the commonest organism with the highest sensitivity for amoxicillin-clavulanic acid in $39.44 \%$, followed by cefotaxime in $27.72 \%$, gentamycin in $20.66 \%$, and amikacin in $10.80 \% .{ }^{4}$ We attribute these differences in bacteriological cultures and antibiotic sensitivity to the varying microbial population and the variable pattern of nosocomial infections in different geographical regions, and different health facilities.

\section{CONCLUSION}

Surgical site infections change the course of a patient's surgical experience dramatically. They increase the mental, financial, and psychological burden on the patient and family. This study was the very first study of its kind in our department and helped us establish the ISSI rate, identify the risk factors and the scope for corrective action and plan further studies. Also, it made us realize that greater effort needs to be put to increase the public awareness on life style issues and adopt this as an important preventive approach to reduce surgical site infectious morbidity.

Funding: No funding sources Conflict of interest: None declared
Ethical approval: The study was approved by the Institutional Ethics Committee

\section{REFERENCES}

1. Theific.org.2019. Available from: http://theific.org/wpcontent/uploads/2014/10/025.pdf. Accessed on 11 September 2019.

2. Wick EC, Hicks C. Bosk CL. Surgical site infection monitoring are two systems better than one? JAMA Surg. 2013:148:1085-6.

3. Letourneau AR, Calderwood MS, Huang SS, Bratzler DW, Ma A, Yokoe DS. Harnessing claims to improve detection of surgical site infections following hysterectomy and colorectal surgery. Infect Control Hosp Epidermiol. 2013:34(12):13213 .

4. Bhadauria A, Hariharan C. Clinical study of postoperative wound infections in obstetrics and gynecological surgeries in a tertiary care set up. Int $\mathbf{J}$ Reprod Contr Obstet Gynecol. 2013;2(4):631.

5. Horan T, Gaynes R, Martone W, Jarvis W, Emori T. CDC Definitions of Nosocomial Surgical Site Infections, 1992: A Modification of CDC Definitions of Surgical Wound Infections. Infect Control Hosp Epidemiol. 1992;13(10):606-8.

6. Lazenby GB, Soper DE. Prevention diagnosis and treatment of gynecological surgical site infections. Obstet Gynecol Clin North Am. 2010:37:379-89

7. Gangane N, Tayade S, Kore J, Kakde P. Surveillance of surgical site infections following gynecological surgeries in a rural setup - Lessons learnt. Indian J Obstet Gynecol Res. 2019;6(1):58-62.

8. Valecha SM, Saswade MN: An original research paper on incidence and risk factors for surgical site infections following major abdominal surgeries in obstetrics and gynecology. Int J Reprod Contracept Obstet \& Gynecol 2017 May: 6(5):1859-1863.

9. Kamel A, Khaled M. Episiotomy and obstetric perineal wound dehiscence: Beyond soreness. J Obstet Gynecol. 2014;34(3):215-7.

10. Pathak A, Mahadik K, Swami MB, Roy PK, Sharma $\mathrm{M}$, Mahadik VK et al. Incidence and risk factors for surgical site infections in obstetric and gynecological surgeries from a teaching hospital in rural India. Antimicrob Resist Infect Control. 2017;6:66.

11. Myles TD, Gooch J, Santolya J. Obesity as an independent risk factor for infectious mobidityin patients who undergo cesarean. Obstet Gynecol. 2002:100:959-64.

12. Chelmow D, Huang E, Strohbehn K. Closure of the subcutaneous dead space and wound disruption after caesarean delivery. J Matern Fetal Neonatal Med. 2002:11:403-8.

13. Shrestha A, Pradhan N. Analysis of the risk factors and microbial etiology of surgical site infections following lower segment caesarean section. Sri Lanka J Obstet Gynecol. 2019;41(1):15. 
14. Cardoso Del Monte M, Pinto Neto A. Post discharge surveillance following caesarean section: The incidence of surgical site infection and associated factors. Am J Infect Control. 2010;38(6):467-72.

15. Pandit A, Sharma P, Yangzom K. Incidence of caesarean wound infection in Patan Hospital Nepal. J Nepal Med Assoc. 2003;42(149):280-3.

16. Bhartiya N, Gupta M, Jain S, Saini V. Anemia: A Risk Factor for Surgical Site Infection Following Caesarean Section. Indian Obstet Gynecol. 2018;8(1):8-15.

17. Narang R, Nandmer G, Sapkal R. Factors affecting post-operative wound gaping and their outcome in obstetrical and gynecological abdominal surgeries. Int J Reprod Contr Obstet Gynecol. 2017;6(4):1530.

18. Naphade SA, Patole K. Study of surgical site infections following gynecological surgeries in a tertiary care hospital. MVP J Med Sci. 2017;4(2):186-92.

19. Malone DL, Genuit T, Tracy JK, Gannon C, Napolitano LM. Surgical site infections: reanalysis of risk factors. J Surg Res. 2002;103(1):89-95.

20. Ibrahim M, Moustafa G, Al-Hamid A, Hussein M. Superficial incisional surgical site infection rate after cesarean section in obese women: a randomized controlled trial of subcuticular versus interrupted skin suturing. Arch Gynecol Obstet. 2013;289(5):981-6.

21. Fehr J, Hatz C, Soka I, Kibatala P, Urassa H, Smith $\mathrm{T}$ et al. Risk factors for surgical site infection in a Tanzanian district hospital:a challenge for the traditional National Nosocomial Infections Surveillance System Index. Infect Control Hosp Epidemiol. 2006;27(12):1401-4.

22. Eriksen HM, Chugulu S, Kondo S, Lingaas E. Surgical Site Infections at Kilimanjaro Christian Medical center. J Hosp Infect. 2003:55:14-20.

23. Dahiya P, Gupta V, Pundir S, Chawla D. Study of incidence and risk factors for surgical site infection after caesarean section at first referral unit. Int J Contemp Med Res. 2016;3(4):1102-4.

Cite this article as: Chandra S, Saxena S. Incisional surgical site infections in obstetric and gynecological procedures in a tertiary care hospital in Northern India. Int J Reprod Contracept Obstet Gynecol 2020;9:4946-52. 